\title{
Bond strength test of acrylic artificial teeth with prosthetic base
}

\author{
Erna Kurnikasari, Muslich Mahmud, Hasna Dziab \\ Department of Prosthodontics Faculty of Dentistry Universitas Padjadjaran
}

\section{ABSTRACT}

Denture consists of acrylic artificial teeth and acrylic prothesis base bond chemically with a bond strength of $315 \mathrm{kgF} / \mathrm{cm}^{2}$. Most of the commercial acrylic artificial teeth do not specify their specifications and all of those acrylic artificial teeth do not include mechanical data (bond strength). The aim of this study is to discover which acrylic artificial teeth meet ADA specification no. 15 . This study is a descriptive analytic study performed to 5 acrylic artificial teeth posterior brands commonly used by dentists and technicians. From each brand, 3 sample teeth were taken. The acrylic artificial teeth were prepared into a rectangular shape and were attached between acrylic prothesis base simulation and jigs. The sample was given tensile load using a Universal Testing Machine. The amount of force that causes the teeth to be fractured was recorded and the bond strength was calculated. The results of the study show that the average value for the five acrylic artificial teeth for the five brands were as followed: Brand A, 125.993 $\mathrm{kgF} / \mathrm{cm}^{2} ; \mathrm{B}, 188.457 \mathrm{kgF} / \mathrm{cm}^{2} ; \mathrm{C}, 175.880 \mathrm{kgF} / \mathrm{cm}^{2} ; \mathrm{D}, 153.373 \mathrm{kgF} / \mathrm{cm}^{2} ; \mathrm{E}, 82.839 \mathrm{kgF} / \mathrm{cm}^{2}$. The data can be tested statistically by using One Way Anova test and Dunnett test (alpha $=0.05$ ). From the study it is concluded that the five acrylic artificial teeth have a bond strength below the ADA specification no. 15 .

Key words: Acrylic artificial teeth, acrylic prothesis base, ADA specification no. 15, bond strength

\section{INTRODUCTION}

Full denture can be defines as a removable dental prothesis aimed at replacing masticatory surface and structures accompanying it from an upper and lower dental arches. The prothesis is made of artifical teeth bonded to a prothesis base. ${ }^{1-3}$ The cervical part of the artificial teeth often shows smaller cross link. This situation will make chemical bonding with prosthetic base resin easier. The bonding can be strengthen by removing the shiny resin dental ridge lap surface. ${ }^{1}$

The acrylic artificial teeth is chemically bound with the acrylic prosthetic base during the manufacturing process. ${ }^{2-6}$ The chemical bound between the artificial teeth and prosthetic base materials that is heat activated is proven to be effective ${ }^{1}$ and not easily detached. ${ }^{7}$

The acrylic resin is one of the restoration and prosthetic materials that are often used. This material is known as the artificial dental base material in 1937, and until now it is still used as the prosthetic base material. ${ }^{8}$

The artificial teeth that meet the ADA (American Dental Association) specification no.159 are made of polyacrylic, polyacrylic filler, polivynil esther co-polimer or mixture of those plastics. The chemical bond between the artificial teeth 
with the acrylic prosthetic base (bond strength) is $315 \pm 10 \mathrm{kgF} / \mathrm{cm}^{2}$ (31 Mpa or $4,500 \mathrm{lb} /$ inch $^{2}$ ), the hardness is no less than $15 \mathrm{kgF} / \mathrm{cm}^{2}$, does not change color or form when it is heated in $100^{\circ} \mathrm{C}$ water for 3 hours. ${ }^{9,10}$ ADA specification no. 15 is used as a guide in specimen preparation and testing and has been determined as a standard for acrylic artificial tooth testing for physical properties such as bond strength, hardness and color stability. 9,11

By looking at the above description and the benefits of acrylic as mentioned above, the acrylic artificial teeth is still used widely until now. However, the acrylic artificial teeth sold commercially under various brands do not include mechanical property data, i.e. bond strength between artificial teeth and the prosthetic base and most of them do not include the specification information. This situation makes it difficult for the consumer, especially medical workers which is dentists, to make a choice based on indications so that the warranty of the material quality becomes the responsibility of the dentist. Therefore, a test to guide artificial tooth selection is necessary that includes test on the bond strength mechanical property of the acrylic artificial teeth.

\section{MATERIALS AND METHODS}

The type of research applied here is the descriptive analytical study. The study sample used includes 5 posterior acrylic artificial tooth brands that are frequently used by operators including dentists and dental staff. From each brand, 3 teeth is selected and prepared into a rectangle. The prepared acrylic tooth is then attached between the acrylic prosthetic base simulation with a diameter of $7.5 \mathrm{~mm}$ and $70 \mathrm{~mm}$ long and a supporting instrument (jig) with a diameter of 7.5 $\mathrm{mm}$ and $10 \mathrm{~mm}$ long.

The sample is made in 4 stages, i.e. preparing acrylic artificial tooth, making prosthetic base simulation wax model, and attaching prepared acrylic artificial teeth with the prosthetic base simulation wax model and jig wax model.

\section{Acrylic artificial tooth preparation}

The acrylic artificial teeth is ground using a micromotor and carborundum disk and green stone into a rectangle which is then measured using vernier calliper for its surface size (length $x$ width) between $4.03 \times 3.60 \mathrm{~mm}-5.91 \times 4.63 \mathrm{~mm}$ ) (Fig. 1).

\section{Making prosthetic base simulation wax model}

Prosthetic base simulation wax model is made of wax baseplate. The model is made into a full cylinder with a length of $70 \mathrm{~mm}$ and a diameter of $7.5 \mathrm{~mm}$ (Fig. 2).

\section{Making jig wax model}

The jig wax model is made of wax baseplate. The model is made into a full cylinder with a length of $10 \mathrm{~mm}$ and a diameter of $7.5 \mathrm{~mm}$ (Fig. 3).

The prepared acrylic artificial teeth is attached to the prosthetic base simulation wax model and jig wax model

Mix plaster gips powder and water with W/ $P$ ratio of 0.5 in the rubber bowl with a spatule. Pour the mixture into the bottom cuvet that has been half filled by plaster gips. Put the prepared tooth between the prosthetic base wax model and jig wax model in the cuvet. The prepared teeth should be in line with the long axis of the prosthetic base wax model and jig wax model. Wait until it is hardened and then spread vaseline onto the cuvet surface. Close the cuvet in metal to metal contact and then pour stone gips until a half full with a similar W/P ratio and method applied for the bottom cuvet until it is hardened and then pour the plaster gips to fill the cuvet and wait until it is hard. Perform wax removal process, put cuvet into cold water and heat up until the water boils.

The wax residual is removed using boiling running water mixed with detergent until all wax is removed. Rinse with clean boiling water. Spread CMS using a brush in the hollow part left by the wax removal process. Mix acrylic powder and liquid with a weight ratio of $2: 1$ in a mixing jar. Pour the plastic acrylic mixture into the cuvet and line it with wet celophane paper and then press. Cooking process: Put cuvet into cold water and then heat the water to $73 \pm 1^{\circ} \mathrm{C}$ for 1.5 hour and maintain the temperature for 30 minutes. Let the cuvet in the water after putting off the fire for 30 minutes until a room temperature for cooling is reached and soak it in running water for 15 minutes. Get the sample out of the cuvet and clean it from the gips (Fig. 5). 


\section{Testing bond strength}

Enter surface size data from the sample into the computer. Put the sample between the two jigs of the Universal Testing Machine. Activate the Universal Testing Machine with a speed of 2.5 $\mathrm{mm} / \mathrm{min}$. The five samples get similar treatment, i.e. its bond strength is calculated with the following rules: Test mode: Single tension; Test speed: 2,500 mm/min; Load cell: $100 \mathrm{KGF} ; \mathrm{F} / \mathrm{s}$ Load: $\left.100.00{ }^{*} 1\right) \mathrm{kgF}$; Chart mode: Forward up connect. The results of this test is a stress that is directly read on the computer screen. Perform similar test to each sample and then calculate the mean and standard deviation.

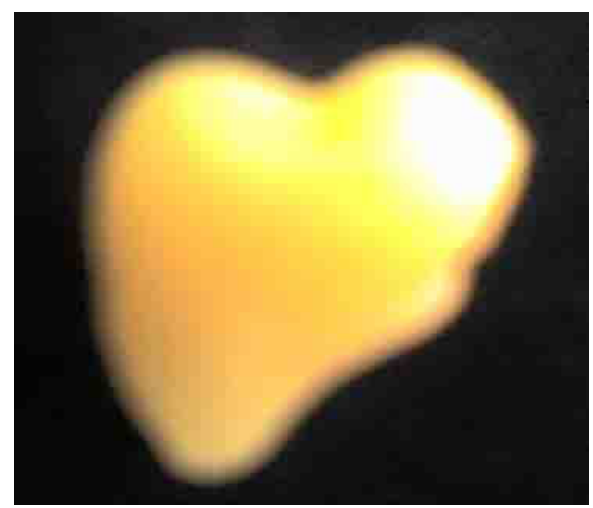

Figure 1. Acrylic artificial teeth before preparation.

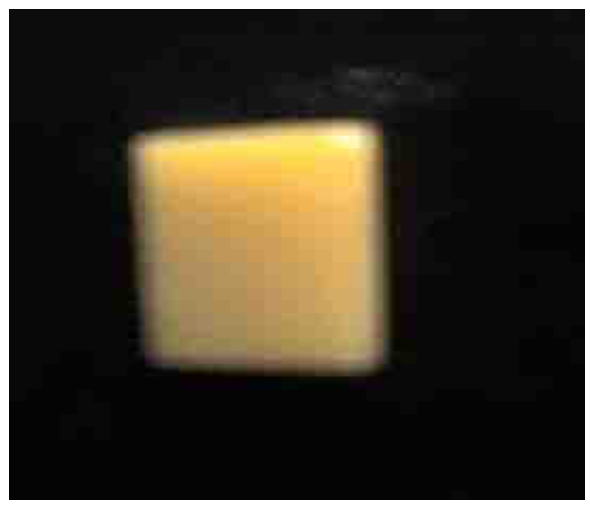

Figure 2. Acrylic artificial teeth after preparation.

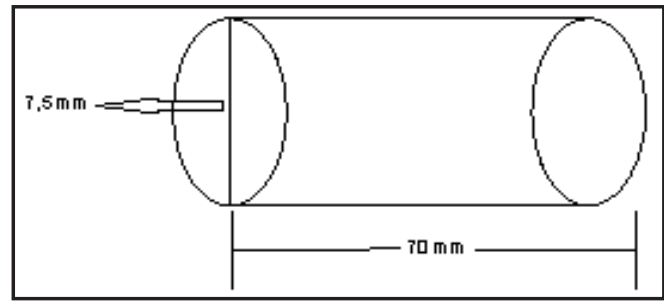

Figure 3. Prosthetic base simulation wax model.

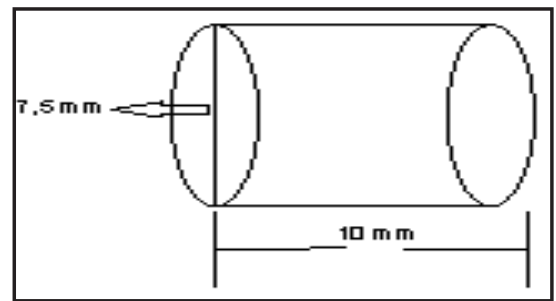

Figure 4. Jig wax model.

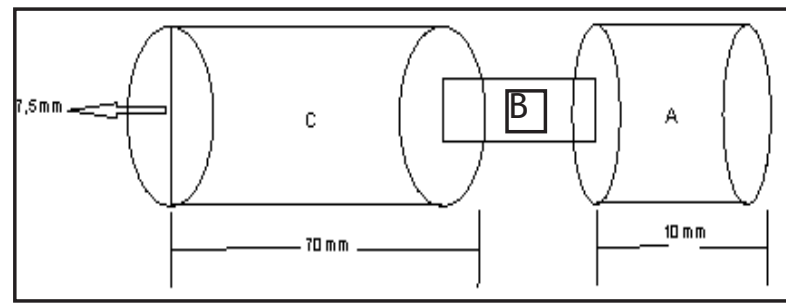

Figure 5. Sample distribution in cuvet. A. Jig wax model; B. Acrylic artificial teeth; C. Prosthetic base simulation wax model.

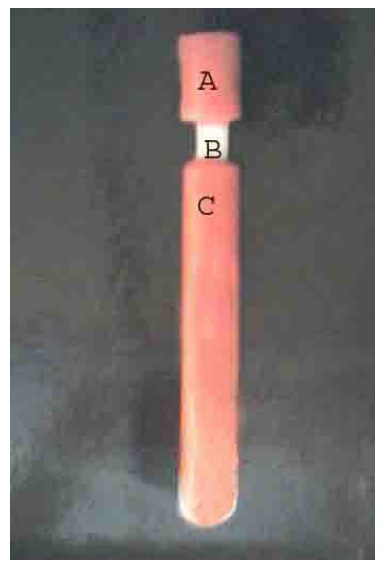

Figure 6. Study sample. A. Jig; B. Acrylic artificial teeth; C. Prosthetic base simulation.

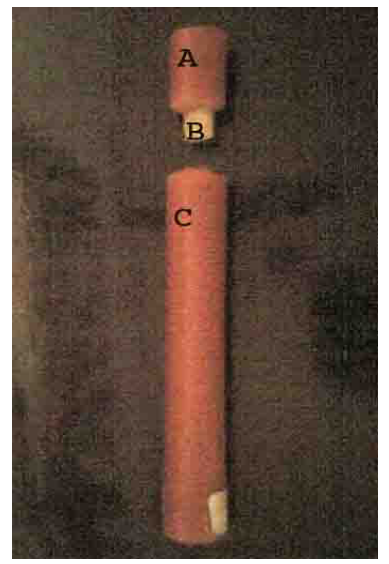

Figure 7. Sample after testing. A. Jig; B. Acrylic artificial teeth; C. Prosthetic base simulation. 


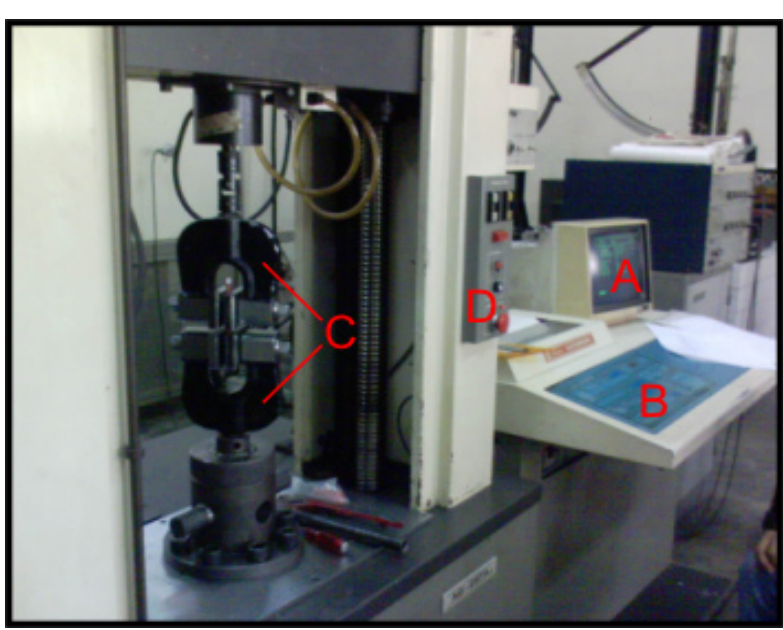

Figure 8. Universal Testing Machine A. Monitor; B. Keyboard; C. Sample jig; D. On/off button.

The data collected from this study is tested analytically using one-way Anava (variant analysis). This analysis is aimed at seeing whether there is a different bond strength in the five artificial tooth brands towards ADA specification standards no. 15. After that a follow up test after the variant analysis is performed using Dunnet test with a significance level of $5 \%$ to see bond strength difference from the five acrylic artificial tooth brands towards ADA specification standards no. 15.

\section{RESULTS}

The results of bond strength measurement between the acrylic artificial teeth with acrylic prosthetic base are as followed in Table 1,2, and 3.

From Table 1 and Diagram 1, it can be seen that the highest mean bond strength value is found in Brand B artificial tooth, i.e. 188,457; Brand D: 153,373; Brand A: 125,993; and Brand C: 175,880. The smaller bond strength value is found in Brand E, i.e. 82,839 .

After the bond strength is collected, a statistical calculation using one way Anava to find out which artificial tooth brand has different bond strength level from the standard is performed From the one way variant analysis table above, it can be concluded that there is a significant difference in bond strength of the five artificial tooth brands and the standard.

Next, due to the difference in the results of the one way Anava, the Dunnet test is performed to see which artificial tooth brands have different bond strength compared to ADA specification no.15. From Dunnet test table above it is revealed that the bond strength of the artificial teeth in the five brands is smaller than the ADA specification. The bond strength of different artificial tooth brand is reduced starting brand $\mathrm{C}$, with a mean difference between $C$ brand with ADA specification of -139.12 . The same is true for Brand $B$, Brand $D$, Brand $A$ and Brand $E$ artificial teeth that have a significantly different bond strength.

\section{DISCUSSION}

Related to the test performed where the bond strength results between the five acrylic artificial tooth brands with acrylic prosthetic base, it is shown that there is a difference with the ADA specification standard no. $15(315 \pm 10 \mathrm{kgF} /$ $\mathrm{cm}^{2}$ ) and that all brands have various values. It is possible that the composition of each brand is different with the most possible different is the cross linked composition. It is possible that there is little, if even exist, cross linked composition in the brand that has the highest bond strength and the opposite is true where the brand with the lowest bond strength has a high cross-linked composition.

Based on the theory of Craig et al. ${ }^{12}$ it is stated that the gingival part of the acrylic artificial tooth is prepared from a material that does not have cross linked or have limited amount of cross linked that make the bond with the prosthetic base better and the occlusal part is prepared from a material that contains cross-linked to improve resistance towards fracture. With a preparation of the gingival part of the acrylic artificial tooth, it is possible that the gingival part with no cross linked or small amount of cross linked is remove that leads to a possibility of reduced chemical reaction of the prosthetic base material with the acrylic artificial teeth that cause weak bond strength.

The principal difference in composition between acrylic artificial teeth and acrylic prosthetic base is the difference in color pigment. ${ }^{12}$ Therefore, there is a possibility that the acrylic artificial teeth and prosthetic base from the same brand has stronger bond strength. In this study, the prosthetic base is made into $70 \mathrm{~mm}$ long and with a diameter of $7.5 \mathrm{~mm} .{ }^{9}$ Therefore, the possibility to create pores is bigger according to Annusavice 
Table 1. Results of bond strength measurement in acrylic artificial teeth with acrylic prosthetic base.

\begin{tabular}{ccccccc}
\hline Brand & & A & B & C & D & E \\
\hline \multirow{2}{*}{ Load (kgF) } & Mean & 24.832 & 44.626 & 40.235 & 29.896 & 18.386 \\
& Standard Deviation & 3.29 & 6.636 & 5.776 & 4.84 & 2.229 \\
\multirow{2}{*}{ Bond Strength } & Mean & 125.993 & 188.457 & 175.88 & 153.373 & 82.839 \\
& Standar Deviation & 11.429 & 6.732 & 8.447 & 13.112 & 12.65 \\
\hline
\end{tabular}

Diagram 1. Result of mean bond strength based on acrylic artificial tooth brand.

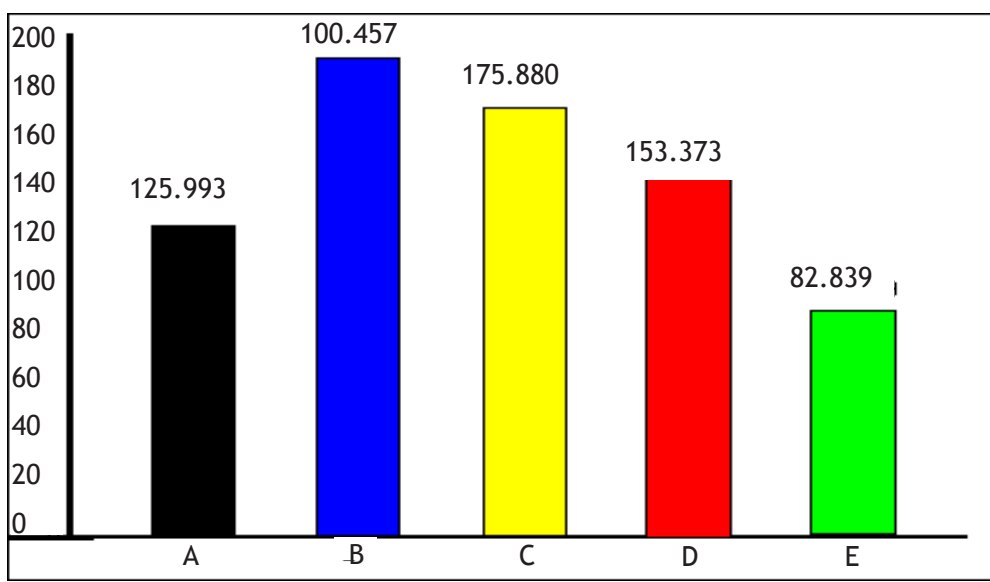

Table 2. One way Anava for bond strength in five acrylic artificial brands and standard.

\begin{tabular}{ccccccc}
\hline Variation source & Db & Total Square & Median Square & F Calc & F Table & Note \\
\hline Between Groups & 5 & 93399.03 & 18679.81 & 193.50 & 3.11 & Sign difference \\
In Group & 12 & 1158.46 & 96.54 & & \\
Total & 17 & 94557.50 & & & \\
\hline
\end{tabular}

Table 3. Dunnett Test to compare bond strength in fve acrylic artificial tooth brands with the standard.

\begin{tabular}{ccccc}
\hline (I) Artificial tooth brand & (J) Control & Mean difference (I-J) & Sig & Note \\
\hline A & Standard & -189.01 & 0.00 & Sign difference \\
B & Standard & -126.54 & 0.00 & Sign difference \\
C & Standard & -139.12 & 0.00 & Sign difference \\
D & Standard & -161.63 & 0.00 & Sign difference \\
E & Standard & -232.16 & 0.00 & Sign difference \\
\hline
\end{tabular}

theory ${ }^{1}$, the porocity will tend to happen in the thicker prosthetic base that will influence the physical properties, esthetic properties and cleanliness of the prosthetic base. Porocity will also weaken the bond strength. ${ }^{13}$

\section{CONCLUSION}

All five acrylic artificial tooth brands have a bond strength under ADA specification standards no. 15. It means that the five acrylic artificial tooth brands do not meet the ADA specification standard no. 15 . Based on the statistical calculation, there is a significant difference between the five acrylic tooth brand with the ADA specification standard no. 15.

\section{REFERENCE}

1. Anusavice KJ. Phillip's science of dental materials. $8^{\text {th }}$ ed. USA: Saunders; 2003. p. 15560.

2. Gladwin M, Bagby M. Clinical aspects of dental materials. USA: Lippincott Williams and 
Wilkins; 2000. p. 130-1.

3. Reese AJ, Valega MT. Restorative dental materials an overview. London: Quintessence Publishing Co. Ltd; 1985. p. 174-8.

4. Hatrick CD, Stephen W, Bird WF. Dental material. Philadelphia: Saunders; 2003. p. 251-4.

5. McGivney PG, Carr AB. Removable partial prosthodontics. USA: Mosby; 2000. p. 1-9.

6. McCabe JF. Applied dental materials. $7^{\text {th }}$ ed. London: Blackwell Scientific Publications; 1990. p. 88,104-5.

7. Anderson JN. Applied dental materials. $5^{\text {th }}$ ed. Melbourne: Blackwell Scientific Publications; 1976. p. 284-5.

8. Craig RG, Powers JC. Restorative dental materials. $11^{\text {th }}$ ed. St. Louis: Mosby Inc.; 2002. p. 672.

9. American Dental Association. Guide to dental materials and devices. $7^{\text {th }}$ ed. Chicago; American Dental Association; 1974. p. 102-3, 212-3.

10. Craig RG. Restorative dental materials. $9^{\text {th }}$ ed. USA: Mosby Inc.; 1993. p. 502,528,536-7.

11. Schneider LR, Erick RC, James MS. Tensile bond strength of acrylic resin denture teeth to a microwave or heat processed denture base. J Prosthet Dent 2002;88:145-50.

12. Craig RG, Powers JM, Wataha JC. Dental materials: Properties and manipulation. $8^{\text {th }} \mathrm{ed}$. St. Louis: Mosby Inc.; 2004. p. 271-2, 286-7.

13. Pudjirochani E. Kekuatan pelekatan anasir gigi akrilik terhadap beberapa macam resin basis gigi tiruan. J Kedokt Gigi PDGI 1990:53-4. 